\title{
Neurofibromatose tipo 1 com manifestação oral: relato de caso e revisão da literatura
}

\author{
Neurofibromatosis type 1 with oral manifestation: a case report and literature review \\ Pollianna Muniz Alves ${ }^{1}$; Cristina Ruan Ferreira de Araújoº ; Jozinete Vieira Pereira3; \\ Francineide Almeida Pereira Martins ${ }^{4}$; Lélia Maria Guedes Queiroz ${ }^{5}$
}

key words
Neurofibromatose 1
Neurofibroma
Língua

\section{abstract}

A neurofibromatose tipo 1 é uma condição hereditária autossômica dominante caracterizada pela presença de tumores benignos na pele, alterações em sistema nervoso, ossos e glândulas endócrinas, e que pode ser acompanhada de leve retardo mental, convulsões, tumores malignos, displasia esquelética e desordem da pigmentação. $\mathrm{O}$ trabalho tem como objetivo relatar o caso de uma paciente portadora de neurofibromatose tipo 1 com manifestação na cavidade oral, representada pela presença de extensa massa nodular na língua, além de fazer uma breve revisão dessa condição. Concluiu-se que, apesar de a neurofibromatose tipo 1 ser uma condição rara que pode apresentar manifestação na cavidade oral, é de extrema importância o seu conhecimento por parte dos cirurgiões-dentistas e da atuação de uma equipe multidisciplinar.

\section{resumo}

Neurofibromatosis type 1 is an autosomal dominant condition characterized by the presence of benign skin tumors, alterations in the nervous system, bones and endocrine glands. It may be followed by mild mental retardation, convulsions, malignant tumors, osseous dysplasia and abnormal pigmentation. The aim of this paper is not only to report the case of a patient with neurofibromatosis type 1 with manifestation in the oral cavity, represented by the presence of a large nodular mass in the tongue, but also to undertake a brief review of this condition. The work concluded that, despite the fact that neurofibromatosis type 1 is a rare condition, which may present manifestations in the oral cavity, its study is of paramount importance to dental surgeons and multidisciplinary groups.

\section{unitermos}

Neurofibromatosis 1

Neurofibroma

Tongue

\section{Introdução}

A neurofibromatose tipo 1 (NF1), também conhecida como síndrome de von Recklinghausen, foi identificada pela primeira vez em 1882 por Friedrich Daniel von Recklinghausen. Caracteriza-se por um processo displásico que afeta os derivados neuroectodérmicos, tecidos mesenquimatosos e ósseos. Independe de raça, sexo e região, ocorre na proporção de 1/4.000 nascimentos e pode-se manifestar logo ao nascimento ou tardiamente ${ }^{(3,5,7)}$.

A alteração genética que produz a NF1 é uma mutação autossômica dominante, com alta penetrância e expressividade variável. O gene NF1 foi mapeado no braço longo do cromossomo 17, clonado e caracterizado como uma proteína Ras-GAP. As mutações que ocorrem no gene NF1, codificando a proteína neurofi-

1. Doutoranda em Patologia Oral pela Universidade Federal do Rio Grande do Norte (UFRN).

2. Doutoranda em Patologia Oral pela UFRN.

3. Professora-doutora de Estomatologia do Departamento de Odontologia da Universidade Estadual da Paraíba (UEPB).

4. Professora-doutora de Patologia Oral do Departamento de Odontologia da Universidade Federal da Paraíba (UFPB).

5. Professora-doutora de Patologia Oral do Departamento de Odontologia da UFRN. 
bromina, causam perda da sua função, conduzindo assim ao fenótipo da NF1 ${ }^{(14,16)}$.

A NF1 caracteriza-se clinicamente pela presença de múltiplas manchas café-com-leite, nódulos de Lisch, gliomas do nervo óptico e neurofibromas dérmicos. Além disso, podemse evidenciar outros sinais, como é o caso de macrocefalia e baixa estatura. As manchas café-com-leite costumam aparecer nos primeiros anos de vida, aumentando em número e tamanho com o decorrer do tempo. Tornam-se maiores com a evolução da doença, principalmente durante o período de gravidez $z^{(1,5,6,10)}$.

O Instituto Nacional de Saúde ${ }^{(9)}$ americano identificou sete importantes componentes da síndrome: 1. presença de manchas café-com-leite; 2 . dois ou mais neurofibromas de algum tipo, ou um neurofibroma plexiforme; 3 . sardas na região axilar ou inguinal; 4. gliomas ópticos; 5 . dois ou mais nódulos de Lish; 6 . distintivas lesões ósseas; 7. um grau primário relativo com NF1 de acordo com os critérios precedidos. Caso o paciente possua pelo menos dois desses critérios é diagnosticado como portador de $\mathrm{NF}^{(7)}$.

No diagnóstico definitivo devem-se incluir procedimentos como biópsia dos neurofibromas, avaliação oftalmológica e auditiva, pesquisa de tumores cerebrais, avaliação radiológica, teste psicológico e de coeficiente de inteligência (QI), bem como avaliação dos níveis de adrenalina e noradrenalina em excreção urinária( ${ }^{(8)}$.

Alguns estudos têm avaliado o grau de transformação maligna da NF1. Segundo Karnes ${ }^{(7)}$ existe um risco estimado em $3 \%$ a $15 \%$ de os pacientes diagnosticados com NF1 sofrerem processo de transformação sarcomatosa, sendo mais comum a malignização para desordens mielóides, rabdomiossarcoma, osteossarcoma e ganglioneurofibroma. De acordo com Kilic et al. ${ }^{(7)}$ essa transformação maligna ocorre em apenas $2 \%$ a $5 \%$ dos casos.

Este trabalho propõe-se relatar um caso clínico de neurofibromatose tipo 1 em uma paciente de 35 anos de idade, assim como realizar uma revisão da literatura, enfatizando o seu diagnóstico pelo cirurgião-dentista.

\section{Relato}

Paciente do gênero feminino, 35 anos de idade, procurou atendimento em uma unidade básica de saúde do município de Pedras de Fogo (PB). Estava acompanhada de seu cônjuge, o qual relatou que ela apresentava problemas mentais, diagnosticados e tratados em um centro de referência em João Pessoa, fazendo uso controlado de medicação. Tal debilidade foi constatada durante a anamnese, na qual a paciente apenas se queixava de uma odontalgia mal definida. Ao exame clínico oroscópico observou-se a presença de uma significativa massa nodular múltipla na borda lateral da língua, de consistência firme à palpação (Figura 1), medindo aproximadamente $4 \mathrm{x}$ $4 \mathrm{~cm}$ de diâmetro. Ao exame ectoscópico visualizou-se a presença de manchas melanodérmicas disseminadas pela pele, pequenos neurofibromas em tronco (Figura 2), face e membros. Foi realizada uma biópsia incisional na região do dorso da língua, e o material foi enviado para análise histopatológica, que revelou células fusiformes delicadas, com núcleos ondulados, entremeados com neuritos em padrão irregular e fibras de colágeno entrelaçados, quadro histológico condizente com neurofibroma (Figura 3). A partir desses achados, procedeu-se à remoção completa da lesão, sob anestesia geral, cujo exame histopatológico (Figuras 4, 5 e 6) encontrou quadro semelhante ao já observado na biópsia incisional.

Diante do diagnóstico de neurofibromatose tipo 1, a paciente foi encaminhada para a realização de uma avaliação multidisciplinar, compreendida por dermatologista, psiquiatra, oftalmologista, neurologista e ortopedista. Estando presente apenas as lesões em pele, boca e o leve retardo mental, concluiu-se o diagnóstico definitivo dessa condição.

A paciente foi mantida em proservação por um período de dois anos, sem serem observados sinais de recidiva da lesão na região do dorso lingual. Após esse período, a paciente abandonou as consultas de proservação, possi-

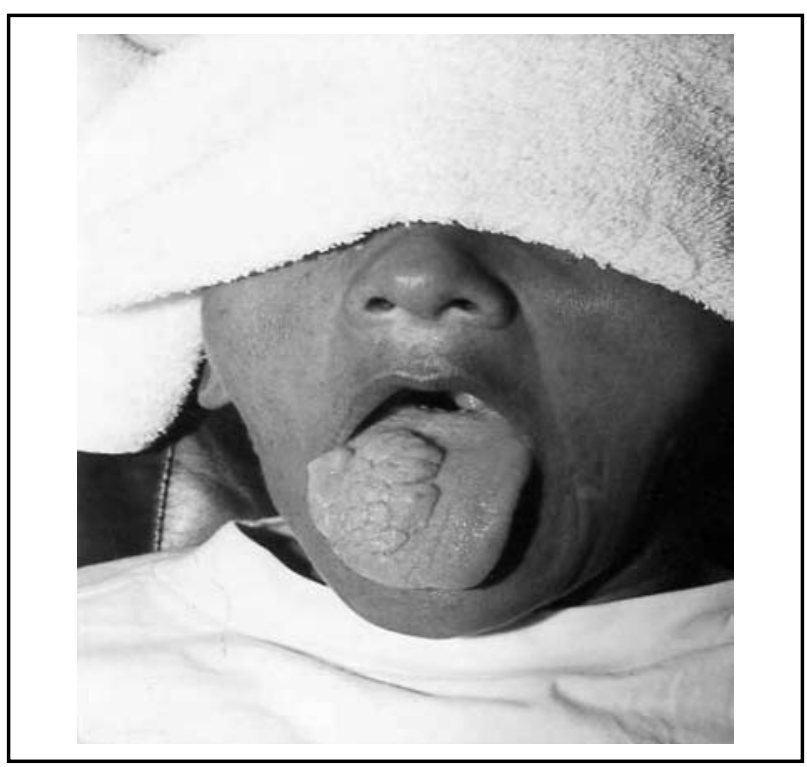

Figura 1 - Neurofibroma localizado no dorso da língua 


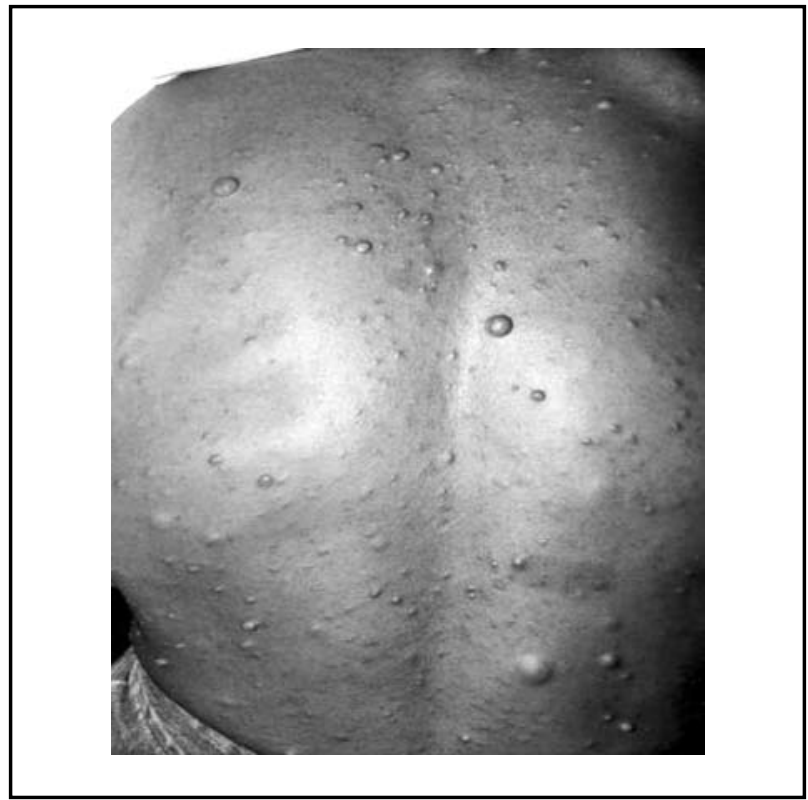

Figura 2 - Neurofibromas e manchas café-com-leite localizadas no tronco da paciente



Figura 3 - Aspecto microscópico $(H E, 4 x)$

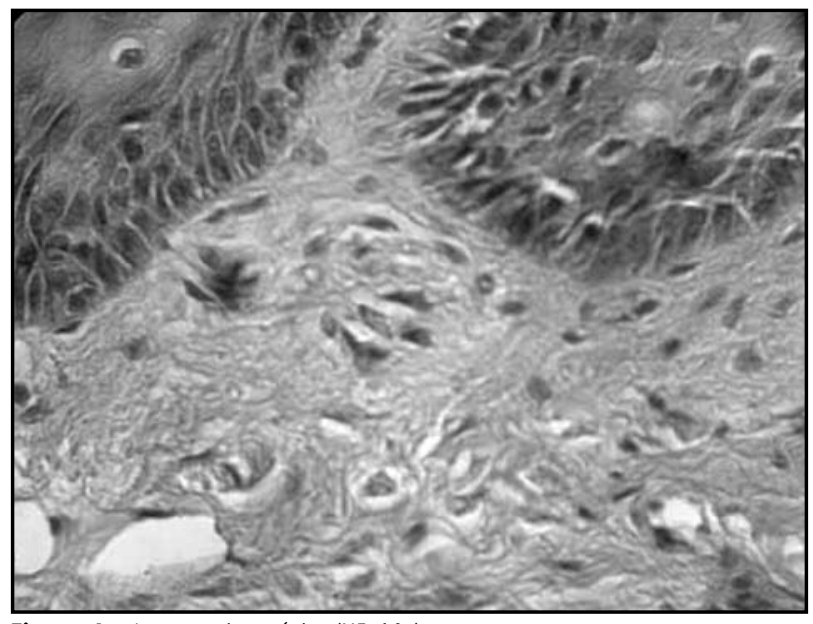

Figura 4 - Aspecto microscópico (HE, 10x)

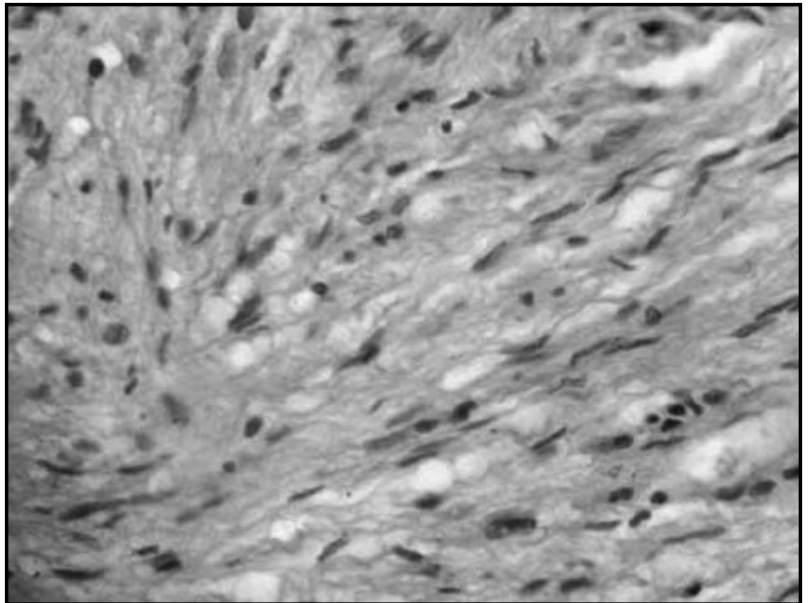

Figura 5 - Aspecto microscópico (HE, 40x)

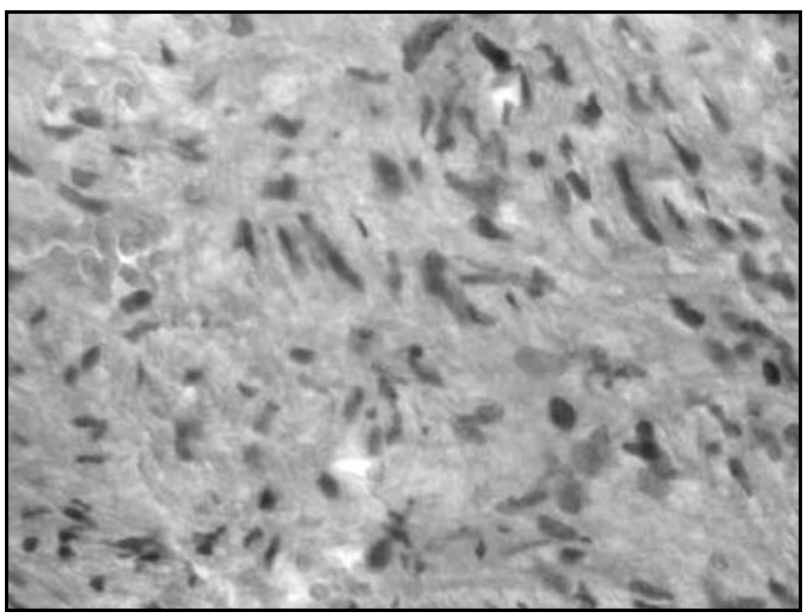

Figura 6 - Aspecto microscópico $(H E, 40 x)$

velmente em função de residir em região de difícil acesso, possuir baixo grau de instrução e não apresentar qualquer sintomatologia.

\section{Discussão}

Duas formas clínicas de neurofibromatose são mais conhecidas: a NF1 e a NF2. Apesar de representadas por desordens genéticas hereditárias autossômicas dominantes, clínica e geneticamente são condições totalmente distintas. A NF1 está associada a alterações genéticas no cromossomo $17^{(2,4,14)}$, caracteriza-se principalmente pela presença de lesões em pele (manchas café-com-leite), tumores no sistema nervoso periférico e anomalias esqueléticas, sendo considerada a segunda afecção genética mais freqüente 
na espécie humana ${ }^{(4,11)}$. A NF2 está associada a alterações genéticas no cromossomo 22 , as lesões em pele são menos pronunciadas e caracteristicamente observa-se a presença de problemas neurológicos e schwannomas vestibulares bilaterais, sendo bem mais rara que a NF1 $1^{(4)}$.

Em geral, a NF1 é diagnosticada clinicamente pelas manifestações cutâneas e pela história familiar. No caso aqui relatado, não havia história de comprometimento familiar da paciente, estando presentes apenas as manifestações cutâneas, mentais e da mucosa oral. Segundo Santos et al.(11) essa patologia é caracterizada pela presença de manchas melanodérmicas e tumores cutâneos, eventualmente acompanhados de alterações mentais, endócrinas, neurológicas e ósseas.

Devido às múltiplas manifestações e complicações na apresentação da síndrome, o atendimento e o acompanhamento de seus portadores freqüentemente envolve vários especialistas, e o tratamento multidisciplinar será individualizado de acordo com as manifestações de cada paciente ${ }^{(13,17)}$.

Na NF1 a incidência para lesões orais é estimada em torno de $10 \%$, mais rara do que nas demais regiões do corpo. Acredita-se que o local mais atingido na cavidade oral seja a língua, freqüentemente apresentando nodulares e unilaterais, o que clinicamente concorda com o caso relatado, que se apresentava como uma massa nodular múltipla e unilateral. A localização na região de palato, ossos da maxila e mandíbula é rara ${ }^{(15)}$.

A presença de neurofibromas pequenos e assintomáticos na língua requer um conhecimento mais acurado, visto que essas lesões inicialmente podem ser confundidas com variações da anatomia intra-oral. As lesões são mais facilmente diagnosticadas quando o paciente queixa-se de aumento de volume ou desconforto. De acordo com Bongiorno, Pistone e Aricó( ${ }^{(3)}$ o diagnóstico diferencial de massas nodulares nessa localização inclui lipoma, angiolipoma, lipoma condróide, miolipoma, lesões hamartomatosas, schwannoma, linfangioma, hemangioma, neurofibroma e neurofibroma plexiforme.

Enaltece-se assim a importância do cirurgião-dentista no diagnóstico das lesões orais, mesmo quando elas não estão relacionadas com a queixa principal do paciente. Caso seja observada a presença de lesões cutâneas, devese encaminhá-lo para as especialidades médicas, como no caso reportado por Darimont e Rompen ${ }^{(2)}$, que mesmo na presença de um aumento unilateral na gengiva, cujo exame microscópico observou proliferação de células de Schwann, presença de manchas café-com-leite e de pequenos neurofibromas por todo o corpo do paciente, apenas chegou-se ao diagnóstico definitivo após avaliação dermatológica, neurológica, oftalmológica e endócrina, apesar de não serem revelados problemas adicionais.

O diagnóstico diferencial de pacientes com manchas pigmentadas deve ser feito com as síndromes de McCune Albright, Peutz-Jeghers e com a doença de Addison, sendo o diagnóstico da neurofibromatose eminentemente clínico, segundo critérios estabelecidos pelo Instituto Nacional de Saúde $(7,9,13)$.

Conforme Bekisz et al. ${ }^{(2)}$ os neurofibromas são a principal característica da NF1 e usualmente aparecem durante a infância ou a adolescência, após o surgimento das manchas café-com-leite.

Bongiorno, Pistone e Aricó(3), em estudo realizado com 258 pacientes de NF1, observaram que apenas três apresentaram lesões nodulares na língua (dois pacientes com neurofibroma e um com neurofibroma plexiforme). Constataram mais uma vez a raridade das manifestações orais da NF1.

Atualmente não há cura para NF1, sendo seu tratamento a ressecção cirúrgica das lesões que comprometem a função e/ou a estética do paciente. Montaño et al. ${ }^{(8)}$, Seller et al.(12) e Simonato et al. ${ }^{(13)}$ ainda enfatizam que a psicoterapia e o acompanhamento social são válidos para restaurar e reconstruir o equilíbrio emocional dos pacientes, pois como essa patologia causa deformidades em algumas partes do corpo, interferindo na estética, isso pode afetar o convívio social do indivíduo.

Um aumento da prevalência de malignidade tem sido relatado em pacientes afetados pela NF1. O desenvolvimento de malignidade pode ocorrer no interior de um neurofibroma plexiforme ou associado a ele. Mudança de tamanho de uma massa preexistente, compressão, ou infiltração das estruturas adjacentes pode indicar transformação maligna ${ }^{(1,14)}$.

Dessa forma, é importante que o cirurgião-dentista esteja atento aos sinais e sintomas característicos da NF1 para firmar um diagnóstico correto, tanto em pacientes que apresentam a doença manifesta quanto naqueles sob risco de desenvolvêla. O encaminhamento do paciente às demais especialidades médicas é de extrema valia para identificar possíveis complicações e realizar tanto o aconselhamento genético quanto $o$ monitoramento da progressão da doença. 


\section{Referências}

1. ALLEN, C. M.; MILORO, M. Gingival lesions of recent onset in a patient with neurofibromatosis - clinical conference. Oral Surg Oral Med Oral Pathol Oral Radiol Endod, v. 84, n. 6, p. 595-7,1997.

2. BEKISZ, O.; DARIMONT, F.; ROMPEN, E. H. Diffuse but unilateral gingival enlargement associated with von Recklinghausen neurofibromatosis. A case report. $J$ Clin Periodontol, v. 27, n. 5, p. 361-5, 2000.

3. BONGIORNO, M. R.; PISTONE, G.; ARICÓ, M. Manifestations of the tongue in neurofibromatosis type 1. Oral Diseases, v. 12, p. 125-9, 2006.

4. FERNER, R. E. N. Neurofibromatosis 1 e neurofibromatosis 2: a twenty first century perspective. Lancet Neurol, v. 6, p. 340-51, 2007

5. GELLER, M. et al. Neurofibromatose: síndrome de von Recklinghausen. 1.histórico, diagnóstico, exames clínicos e laboratoriais. J Bras Med, v. 75, n. 3, p. 15-21, 1998.

6. KARNES, P. S. Neurofibromatosis: a common neurocutaneous disorder. Mayo Clin Proc, v. 73, n. 11, p. 1071-6, 1998.

7. KILIC, S. et al. Common variable immunodeficiency in a patient with neurofibromatosis. Pediatrics International, v. 43, p. 691-3, 2001.

8. MONTAÑO, A. et al. Neurofibromatose: revisão de literatura. J Bras Med, v. 69, n. 4, p. 46-54, 1995.

9. NATIONAL INSTITUTE OF HEALTH CONSENSUS DEVELOPMENT CONFERENCE. Neurofibromatosis. Arch Neurol, v. 45, n. 8, p. 575-8, 1988.
10. SADDY, E. M. V. et al. Neurofibromatose: 1. Dados epidemiológicos e etiológicos. Aspectos genéticos e dermatológicos. An Bras Dermatol, v. 60, n. 6, p. 371-8, 1985.

11. SANTOS, M. L. L. et al. Manifestação clínica familiar em pacientes com defeito neuromesodérmico. Arq Neuropsiquiatr, v. 64, p. 798-801, 2006

12. SELLER, M. et al. Neurofibromatose: síndrome de von Recklinghausen. 5. orientação, tratamento, prognóstico e neoplasias. J Bras Med, v. 76, n. 6, p. 121-4, 1999.

13. SIMONATO, L. E. et al. Neurofibromatose múltipla: acompanhamento clínico e radiográfico de 10 anos. Cienc Odontol Bras, v. 9, n. 4, p. 92-8, 2006.

14. STEVENSON, D. A. et al. Clinical and molecular aspects of an informative family with neurofibromatosis type 1 and Noonan phenotype. Clin Genet, v. 69, p. $246-$ 53, 2006.

15. TRIPI, T. R.; BONACCORSO, A. Neurofibromatosis of von Recklinghausen. Minerva Stomatol, v. 47, n. 11, p. 617-22, 1998.

16. VISKOCHIL, D. H. Genetics of neurofibromatosis 1 and the NF1 gene. J Child Neurol, v. 17, p. 562-70, 2002.

17. WOLKENSTEIN, P. et al. Cost evaluation of the medical management of neurofibromatosis 1: a prospective study on 201 patients. British Journal Dermatology, v. 142, p. 1166-70, 2000. 